\title{
Trombectomia Intracoronária. Uma Alternativa no Manejo das Síndromes Isquêmicas Agudas
}

\author{
Rogério Sarmento-Leite, Paulo R. M. Machado, Sinara L. Garcia, Antônio Satyro Neto, Jorge P. Ribeiro
}

Porto Alegre, RS

Apesar do bloqueio agressivo da ativação plaquetária com a associação de aspirina, tienoperidinas e inibidores da glicoproteína IIb/IIIa, e da anticoagulação sistêmica com heparina, a presença de grandes quantidades de trombos intracoronários continua sendo um fator limitante no sucesso da terapêutica de revascularização miocárdica percutânea. Secundariamente à embolização distal, dano à microcirculação e prejuízo da função endotelial pode haver severo comprometimento do fluxo coronário. Um homem de 72 anos com quadro de síndrome isquêmica aguda foi levado ao laboratório de hemodinâmica e a angiografia mostrou uma estenose subtotal com grande presença de trombo no terço proximal da artéria circunflexa (fig. 1). Optou-se por iniciar infusão de abciximab e realizar angioplastia da lesão culpada. Imediatamente após a pré-dilatação com balão, houve maciço tromboembolismo distal com severo comprometimento do fluxo coronariano caracterizando o fenômeno de no-reflow (fig. 2). A única maneira para restauração do fluxo coronário TIMI III foi através da técnica de trombectomia com uso do cateter $X$-sizer (EndiCOR Medical Inc., San Clemente, Califórnia) seguida do implante de um stent. O resultado angiográfico final foi excelente (fig. 3). Esta seqüência de imagens ilustra um novo e alternativo método para o intervencionista no manejo dos pacientes em que as técnicas e dispositivos convencionais não são suficientes na abordagem das síndromes isquêmicas agudas.

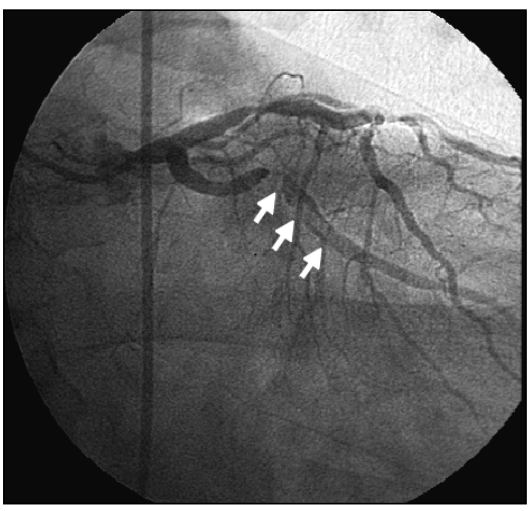

Fig. 1 - Injeção em projeção ântero-posterior caudal mostrando uma estenose subtotal com presença de grande quantidade de trombo no terço proximal da artéria coronária circunflexa.

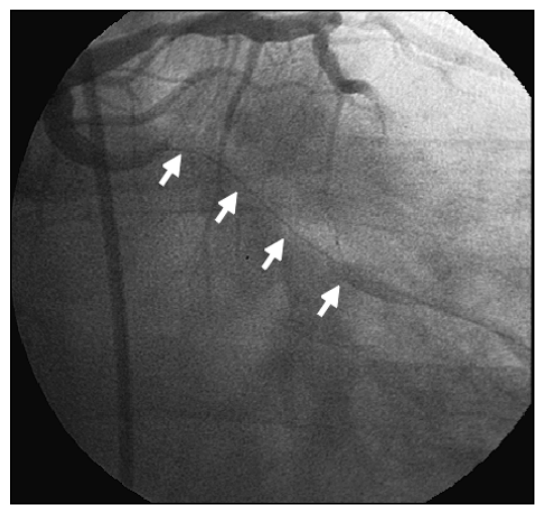

Fig. 2 - Injeção em projeção ântero-posterior caudal realizada após a pré-dilatação com balão, mostrando o vaso com contraste retido ao longo de seu trajeto caracterizando o fenômeno de no-reflow.

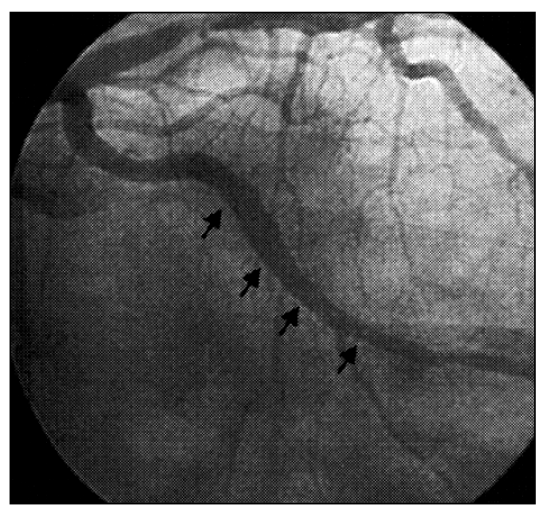

Fig. 3 - Injeção em projeção ântero-posterior caudal realizada após a trombectomia e implante de stent demonstrando recuperação total do calibre e fluxo coronariano.

\section{Referências}

1. Moreno R, Garcia E, Acosta J, Luis Lopez-Sendon J. Treatment of acute myocardial infarction with the $\mathrm{x}$-sizer coronary thrombectomy device. Rev Esp Cardiol 2001; 54: 793-6.
2. Ischinger T, X-SIZER Study Group. Thrombectomy with the X-SIZER catheter system in the coronary circulation: initial results from a multi-center study. J Invasive Cardiol 2001; 13: 89-92. 